\title{
Árboles del Valle Central de Costa Rica: reproducción
}

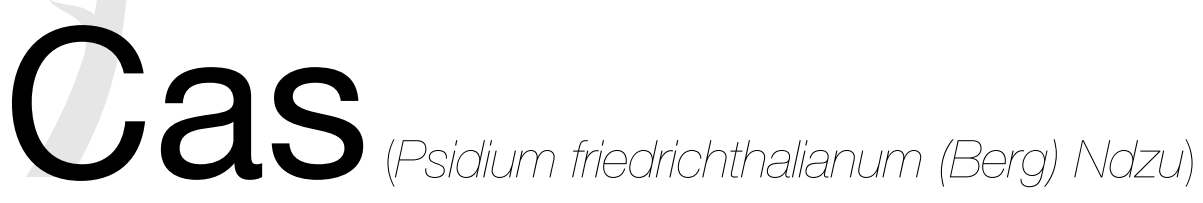

\section{Resumen}

Se presenta una breve descripción del árbol de cas Psidium friedrichthalianum (Berg) Ndzu., información sobre fenología como base para la recolección de frutos, el manejo de las semillas, la viverización y el proceso de germinación.

Palabras clave: Psidium friedrichthalianum (Berg) Ndzu., fenología, manejo de semillas, viverización, germinación, árboles, Costa Rica.

\section{Abstract}

Trees of the Central Valley of Costa Rica:reproduction. Cas. The following issue presents a brief description about the "cas" tree (Psidium friedrichthalianum (Berg) $\mathrm{Ndzu}$.) including information about its phenology which directly relates to fruit recollection, seed treatment, nursery, and germination processes.

Key words: Psidium friedrichthalianum (Berg) Ndzu, phenology, seeds treatments, management at nursery, germination, trees, Costa Rica.

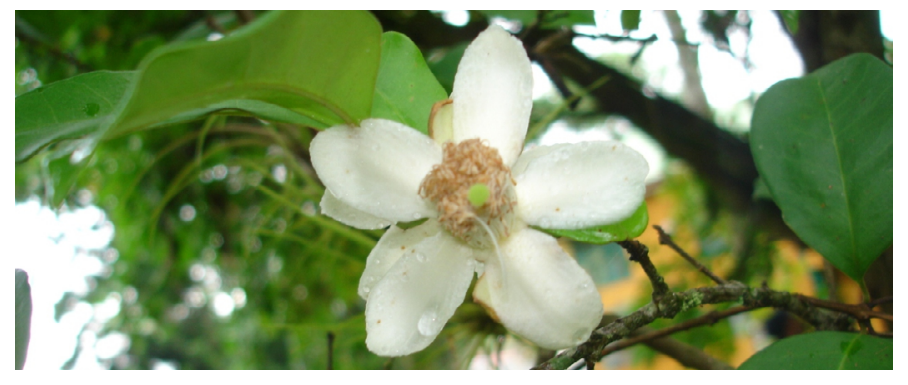

Figura 1. Flor del árbol de cas

\section{Taxonomía}

Nombre científico: Psidium friedrichthalianum (Berg)

Ndzu.

Nombre común: Cas, guayaba agria, guayaba de fresco, guayaba de danto (Geilfus 1989).

Familia: Myrtaceae

Origen: Nativa

\section{Distribución en el mundo}

Desde el sur de México, hasta Colombia.

\section{Distribución en Costa Rica}

Uno de los árboles más comunes en patios y lotes del Valle Central de Costa Rica y de otras regiones del país. 


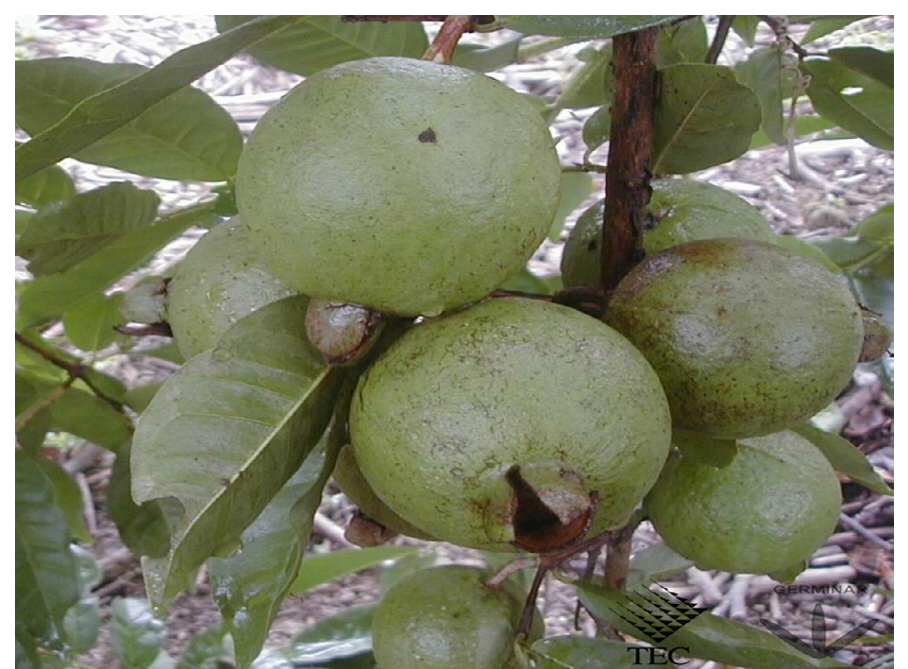

Figura 2. Frutos de cas

\section{Descripción}

Árbol de mediano tamaño tipo arbusto, de copa globosa. Presenta ramas rojizas, follaje abundante verde intenso. La corteza es de color café rojiza con manchas grisáceas y desprendible.

Presenta un follaje perennifolio, sus hojas son simples, opuestas. Pecíolos cortos, borde entero, de color verde oscuro en el haz y pálidas en el envés. Lustrosas, sus ramitas son cuadrangulares.

Sus flores son solitarias, perfectas, blancas de $15 \mathrm{~cm}$ de largo.

Produce frutos carnosos tipo bayas, globosos de 3 a $5 \mathrm{~cm}$ de diámetro. Cáscara verde amarillenta y pulpa suave, ácida, blanca y sabrosa. Las semillas presentan una forma aplanada, de aproximadamente $0,8 \mathrm{~cm}$ de largo. De testa color verde oscuro, lisa, brillante, lustrosa y muy dura. (Torres et al. 2011).

\section{Dendrofenocronograma}

Se presenta a continuación información fenológica de cas, para el Valle Central de Costa Rica.

\begin{tabular}{|c|c|c|c|c|c|c|c|c|c|c|c|c|}
\hline \multirow{2}{*}{ Características } & \multicolumn{12}{|c|}{ Meses del año } \\
\hline & E & $\mathbf{F}$ & M & A & M & $\mathrm{J}$ & $\mathbf{J}$ & A & s & 0 & $\mathrm{~N}$ & D \\
\hline Hojas & & & & & & & & & & & & \\
\hline Flores & & & & & & & & & & & & \\
\hline Frutos verdes & & & & & & & & & & & & \\
\hline Frutos maduros & & & & & & & & & & & & \\
\hline
\end{tabular}

Figura 3. Dendrofenocronograma del cas en el Valle Central, Costa Rica

\section{Manejo de semilla y viverización}

Los frutos de cas se recolectan de noviembre a agosto. Su madurez se reconoce por su color, dispersión y textura.

Para logar la germinación, las semillas deben ser debidamente secadas después de su procesamiento. Se siembran al voleo en un sustrato a base de tierra más arena, y se deben cubrir apenas superficialmente. La germinación se experimenta entre 20 - 37 días después de la siembra. Su porcentaje de germinación, dependiendo de la calidad de la semilla, varía de un 60 a 84\%.

Las plántulas se encuentran listas para su repique o transplante, bajo el sistema de producción en bolsa plástica, una semana posterior a la germinación. En cuanto al mantenimiento, es recomendable aplicar sombra por un periodo no mayor a los 8 días, así como fertilización química u orgánica una vez que superen los 12 a $15 \mathrm{~cm}$ de altura. (Torres et al. 2011).

\section{Proceso de Germinación}

El tipo de germinación de cas es epígea, según la siguiente ilustración.

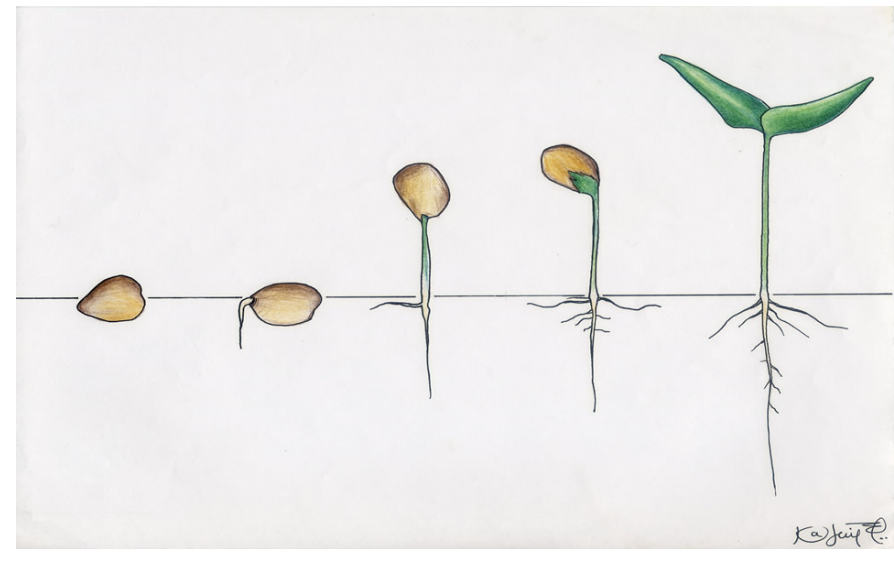

Figura 4. Proceso de germinación del cas

\section{Referencias}

Geilfus, F. 1989. El árbol al servicio del agricultor: Manual de agroforestería para el desarrollo rural. Editorial Santo Domingo. Santo Domingo, República Dominicana. p. 167

Torres, C., Carvajal, D., Rojas, F., Arguedas, M. 2011. Reproducción de especies arbóreas y arbustivas de la región central de Costa Rica. Germinar. (en línea). Cartago, CR, Instituto Tecnológico de Costa Rica. Esc. de Ing. Forestal. Consultado: 15 de mayo 2013. Disponible en: http://www.tec.ac.cr/sitios/Docencia/forestal/Germinar/ germinar\%202.html 